University of Rhode Island

DigitalCommons@URI

Institute for Immunology and Informatics

Institute for Immunology and Informatics

Faculty Publications

(iCubed)

$10-14-2015$

\title{
Analysis of Cell-Mediated Immune Responses in Support of Dengue Vaccine Development Efforts
}

\author{
Alan L. Rothman \\ University of Rhode Island, alan_rothman@uri.edu \\ Jeffrey R. Currier \\ Heather L. Friberg \\ Anuja Mathew
}

Follow this and additional works at: https://digitalcommons.uri.edu/immunology_facpubs

The University of Rhode Island Faculty have made this article openly available.

Please let us know how Open Access to this research benefits you.

This is a pre-publication author manuscript of the final, published article.

Terms of Use

This article is made available under the terms and conditions applicable towards Open Access Policy Articles, as set forth in our Terms of Use.

Citation/Publisher Attribution

Rothman, A. L., Currier, J. R., Friberg, H. L., \& Mathew, A. (2015). Analysis of cell-mediated immune responses in support of dengue vaccine development efforts. Vaccine, 33(50), 7083-7090.

Available at: http://dx.doi.org/10.1016/j.vaccine.2015.09.104

This Article is brought to you for free and open access by the Institute for Immunology and Informatics (iCubed) at DigitalCommons@URI. It has been accepted for inclusion in Institute for Immunology and Informatics Faculty Publications by an authorized administrator of DigitalCommons@URI. For more information, please contact digitalcommons-group@uri.edu. 
1 Analysis of cell-mediated immune responses in support of dengue vaccine development efforts

2

3 Alan L. Rothman ${ }^{a}$, Jeffrey R. Currier ${ }^{b}$, Heather L. Friberg ${ }^{c}$, Anuja Mathew ${ }^{d}$

4

5 anstitute for Immunology and Informatics and Department of Cell and Molecular Biology, University of

6 Rhode Island, 80 Washington St., Providence, RI 02903 USA, e-mail: alan rothman@uri.edu

$7 \quad$ birus Diseases Branch, Walter Reed Army Institute of Research, 503 Robert Grant Ave., Silver Spring,

8 MD, e-mail: jeffrey.r.currier.ctr@mail.mil

9 'Virus Diseases Branch, Walter Reed Army Institute of Research, 503 Robert Grant Ave., Silver Spring,

$10 \mathrm{MD}$, e-mail: heather.I.friberg-robertson.ctr@mail.mil

11 Institute for Immunology and Informatics and Department of Cell and Molecular Biology, University of

12 Rhode Island, 80 Washington St., Providence, RI 02903 USA, e-mail: $\underline{\text { mathewa@uri.edu }}$

13

14 Corresponding author: Alan L. Rothman, University of Rhode Island, 80 Washington St., Providence, RI

1502903 USA, e-mail: alan rothman@uri.edu

16 


\section{Abstract}

vaccine-induced immune responses correlate with vaccine efficacy can greatly accelerate development,

20 testing, and deployment as well as ameliorate potential risks and safety concerns. Advances in basic

21 immunology knowledge and techniques have already improved our understanding of cell-mediated

22 immunity of natural dengue virus infection and vaccination. We conclude that the evidence base is

23 adequate to argue for inclusion of assessments of cell-mediated immunity as part of clinical trials of

24 dengue vaccines, although further research to identify useful correlates of protective immunity is 25 needed. 
The immunological basis of the efficacy of many of the most well-established vaccines is poorly understood, and, where studies to better understand vaccine efficacy have been done, they have almost always relied on tests of pathogen-specific antibodies rather than on measures of cell-mediated

31 immunity (CMI) [1]. Several reasons likely explain this bias; serum is more easily obtained than viable 32 lymphocytes, antibodies can be studied in isolation, and assays of antibody concentration and function

33 are technically more straightforward and reproducible than cellular assays. Fortunately, in many cases

34 detection of antibodies at or above a defined concentration using specific assays has proven to serve as

35 a useful correlate of protective immunity. However, there has been ample evidence in the case of established vaccines that the information provided by assays of antibody responses is often incomplete,

37 and that protective immunity (sometimes only partially protective) was present in some individuals

38 without protective antibody levels.

A consultation was organized by the WHO in 2007 to "review the state of the art of dengue CMI and to discuss the potential role of CMI in advancing dengue vaccine candidates towards licensure" [2].

41 The participants concluded that "precise function of CMI in protection or disease pathology remains ill-

42 defined and, at present, there is no evidence to suggest that CMI can be utilized as a correlate of

43 protection." Recent data from dengue vaccine trials has renewed interest in addressing this issue,

44 however. In the pivotal phase III trials of the Sanofi Pasteur chimeric dengue virus (DENV) - yellow fever 45 virus (YFV) vaccine, plaque reduction neutralization titers (PRNT) only weakly correlated with protection, 46 and breakthrough infections occurred in some individuals with high PRNT values $[3,4]$. While efforts 47 continue to refine assays of DENV-specific antibodies in order to discriminate effective/protective from 48 ineffective/non-protective antibodies (assuming that this is possible), these findings re-emphasize the need to consider the role of DENV-specific T lymphocyte responses in vaccine efficacy. This review seeks 
to summarize the current state of knowledge regarding DENV-specific CMI and propose potential

51 contributions of $\mathrm{CMI}$ measurements to dengue vaccine development and testing.

An appraisal of the literature on DENV-specific T cell responses merits a brief review of current

53 paradigms in T cell biology and relevant technologies. One area highlighted by recent work is the

54 complexity of effector T cell subsets. Extending the paradigm of Th1 versus Th2 responses among CD4 T

55 cells, at least 7 different phenotypes have now been described $[5,6]$. Table 1 summarizes key proteins

56 expressed by each subset. Cytokines and other signals produced by antigen-presenting cells during the

57 initial T cell activation (not listed in the table) determine which pathway is taken by an individual T cell

58 through the induction of the transcription factors listed, and this in turn controls the profile of

59 chemokine receptors and cytokines produced. The characteristic cytokines produced by each subset are

60 the major determinant of its role in immunity and also tend to reinforce cell polarization. The profile of

61 chemokine receptors expressed by each cell subset determines that subset's predominant anatomical

62 distribution, such as peripheral versus mucosal versus secondary lymphatic sites, which also contributes

63 to its function in the response to different pathogens. Cytolytic activity, not traditionally considered an

64 important effector function of CD4 T cells, has been increasingly recognized, mainly among cells

65 expressing Th1 cytokines [7]. In contrast, while cytolysis has long been seen as the main function of CD8

66 T cells, there has been a growing recognition of more diverse subsets within this population. CD8 T cell

67 subsets with cytokine profiles similar to several of the CD4 subsets listed in Table 1 have been described,

68 although there is comparably less known about them. Based on studies in mice, T cell polarization has

69 often appeared to be a fixed characteristic of the cell determined during its initial activation. However,

70 studies in humans suggest more plasticity in T cell phenotype [8].

71 Another area of active research in T cell biology is the developmental relationships between

72 naïve, effector, and memory T cells [9-11]. This topic entails significant debate, as, unlike the case with B

73 lymphocytes, there are no universally accepted standards for defining a memory $T$ cell; several different 
74 schemas have been proposed to define the phenotypes of effector versus memory T cells, but it is clear

75 that these are imperfect. From a functional standpoint, it is recognized that, among antigen-experienced

76 T cells, there is a subset of short-lived effector cells that are destined to undergo apoptosis whereas

77 other cells demonstrate the capacity for long-term persistence and even self-renewal. Within the long-

78 lived memory cell population, heterogeneity in function and protein expression led to a distinction of

79 central memory T cells $\left(T_{C M}\right)$ and effector memory $T$ cells $\left(T_{E M}\right)$. Recent data have revealed further

80 complexity, and led to the classification of several additional subsets such as tissue-resident memory $\mathrm{T}$

81 cells $\left(T_{R M}\right)$ and stem memory $T$ cells. Rather than fixed cell fates, however, there is evidence that these

82 phenotypes retain some degree of plasticity. The timing and determinants of the transitions between

83 states are not fully understood, and remain an important area of investigation. Several markers have

84 been clearly identified as strongly associated with a cell's capacity for long-term survival, such as high

85 expression of IL-7R and low expression of KLRG1.

86

87 Assay methods

Persisting antibody following vaccination is recognized as the first line of defense against

89 subsequent infection and is regarded as a distinguishing characteristic of an effective vaccine [12]. All

90 currently licensed anti-viral vaccines elicit a robust antibody response that correlates with the level of

91 protection provided by the vaccine [13]. If the same should prove to be true for dengue, then the search

92 for a CMI "correlate of protection" for dengue would be unnecessary. However, dengue is one of several

93 globally important infectious diseases, along with HIV, malaria, and tuberculosis, for which a vaccine is

94 highly desirable yet no validated animal model or correlate of immune protection is known. While

95 empirical testing of candidate vaccines has been successful in the past, the era of molecular biology has

96 led to an explosion of tools and methodologies for creating new vaccine antigens and vector delivery

97 systems. The contribution of CMI, particularly T cells, to a successful dengue vaccine is highly likely 
whether it be as direct effector cells, provision of help for antibody development or creating a

99 generalized anti-viral environment. Together with the antigenic complexity of candidate dengue vaccines (Table 2), assessing $T$ cell responses presents a logistical problem for both vaccine developers and clinical testing laboratories - how to test or screen for all possible T cell functions when the most relevant function(s) are unknown.

Fortunately, T cell-based immunoassay development has also proceeded at a remarkable rate

$104[14,15]$. A list of assays together with their advantages and disadvantages is presented in Table 3.

105 Recently the focus of immune-monitoring has been upon assays that provide "minimal manipulation."

106 Relatively high-throughput assays such as ELISPOT and intracellular cytokine staining (ICS), which utilize

107 in vitro stimulation times of less than 24 hours (or no stimulation in the case of direct ex vivo flow

108 cytometry), are the assays of choice as a screening tool. When well qualified, both platforms are 109 quantitative and specific for the antigen. While validation of ELISPOT and ICS assays is not trivial, it is 110 possible, and if a T cell-based correlate of protection for dengue is defined one of these platforms would 111 most likely be the basis of such an assay $[16,17]$. The general disadvantage of ELISPOT assays is that 112 some $a$ priori knowledge of the relevant functions is required. IFN- $\gamma$ has been used extensively in vaccine 113 development as a marker of vaccine take and as a function that is necessary, but perhaps not sufficient,

114 for protection. ICS expands upon the functional profile of ELISPOT assays, bringing the concept of 115 polyfunctionality of T cells to the fore. Again, some a priori knowledge of the relevant functional profile 116 is required to fully interpret the results of this assay. Furthermore, ELISPOT and ICS assays are best 117 suited for measuring and quantifying the direct effector capacity of T cells (IFN- $\gamma$, TNF $\alpha$, and cytolytic 118 potential), but are significantly less sensitive at measuring T cell helper capacity. Mass cytometry and 119 advanced polychromatic flow cytometry are technologies that permit the analysis of as many as 36 120 parameters simultaneously on a single cell. These parameters may include both phenotypic and 121 functional markers. While these methods will facilitate high-dimensional, quantitative analysis of 
122 biomolecules on cell populations at single-cell resolution, their application to dengue research has so far 123 been limited $[18,19]$.

The most sensitive assays are generally those that involve proliferation of a small number of

125 antigen-specific precursor cells. Dye-dilution based T cell proliferation, when appropriately calibrated, 126 can identify the phenotype of proliferating T cells as well as quantify the precursor frequency [20]. In

127 addition, cytokines associated with helper (e.g., IL-4, IL-5, IL-13, IL-21) or regulatory (e.g., IL-10, TGF- $\beta$ )

128 capacity can be studied in supernatants collected from proliferation assays. This approach does however

129 digress from the minimal manipulation concept, is less reproducible and is prone to in vitro variation 130 artifact.

Microfluidics-based technologies have led to the possibility of extensive transcriptional profiling

132 of T cells at the single-cell level and a description of the population dynamics of T cell responses. While

133 better suited to a research-based environment, these methodologies provide a discovery platform that

134 will deliver the best opportunity to uncover a correlate of protection [21, 22]. Ultimately a thorough

135 profiling of the entire "immune space" that is occupied by a dengue vaccine will be required to compare

136 and contrast different vaccine modalities and vaccination strategies [23]. Describing the quality, quantity

137 and durability of immune responses elicited will involve a standardized approach incorporating many of

138 assay procedures listed above and probably new technologies as they become deployable.

139 Should a CMI correlate of protection from dengue infection be identified, a significant effort will

140 be required to qualify and validate assays platforms that will reliably detect and/or measure the

141 correlate or function. As described earlier, validation of ELISpot or ICS format assays has proved

142 possible; however, the further challenge will be applying these assays to meet the needs of the global

143 dengue vaccine research community. The field would benefit from the establishment of centralized

144 laboratory(s) that implement External Quality Assurance (EQA) Programs for overseeing the

145 development of external proficiency testing programs for flow cytometry, ELISpot and other CMI-based 
assays [24-27]. EQA programs serve three purposes and are run according to Good Clinical Laboratory

147 Practice (GCLP) guidance: 1) provide a means for laboratories to ensure that the data generated are 148 accurate, timely and clinically relevant; 2 ) provide assurance to sponsors that the data is reliable and

149 high quality; and 3) ensure the appropriate and accurate use of human specimens obtained from clinical

150 trials. In addition to EQA programs, the establishment of biorepositories of standardized qualified

151 reagents and antigens (e.g. PBMCs, peptide sets, viral isolates) for use in helping laboratories validate

152 assays would be invaluable [28-30]. Such programs have proved successful for the field of HIV vaccine

153 testing, with the EQAPOL program run by the NIH Division of AIDS, and the field of cancer T cell therapy,

154 with the immunomonitoring program run by the Cancer Immunotherapy Consortium

155 (http://www.cancerresearch.org/cic) [24, 31, 32].

\section{$157 \quad$ T cell responses to DENV}

Human T cell responses to DENV were first characterized over 30 years ago, and many of the

159 general principles originally described have remained consistent [33, 34]. Infection with one DENV

160 induces both CD4 and CD8 memory T cells specific for DENV epitopes, with a small number of epitopes

161 dominating the response in each individual. Epitopes are located throughout the DENV polyprotein,

162 although several regions, especially the nonstructural protein 3 (NS3), appear to have a concentration of

163 immunodominant epitopes. The amino acid homology across the four DENV serotypes varies for each

164 epitope; however, most epitopes are well conserved among strains within the same serotype and differ

165 at relatively few positions ( 1 to 3 of 9 residues) from the corresponding epitopes of other DENV

166 serotypes (and other flaviviruses). The overall T cell response induced by a primary DENV infection is

167 strongest to the serotype to which the subject had been exposed, but variable degrees of cross-

168 reactivity are usually observed to one or more of the other serotypes. 
Notwithstanding the confirmation of the above paradigms, the greater understanding of T cell

170 biology and advancements in techniques for analysis of T cell responses described above have provided

171 a more detailed and complex picture, particularly with regard to the different characteristics of the

172 memory $T$ cell response and their potential functions during the recall response to a subsequent DENV

173 infection. Inasmuch as vaccination is intended to induce an immune response that will protect against

174 infection or disease during a subsequent DENV exposure, these findings are highly relevant to evaluating

175 the immunogenicity of different vaccine regimens. However, extrapolating observations from natural

176 DENV infection to current vaccines is confounded by several important differences, as will be discussed

177 further below.

178

179 Survey of recent literature

The pace of scientific publications describing the T lymphocyte response to DENV has greatly

181 accelerated in recent years. A review of PubMed entries showed at least 38 papers published since 2005

182 that analyzed human DENV-specific T cell responses based either on functional responses to stimulation

183 by DENV antigens or staining by HLA-peptide tetramers containing DENV peptides, 26 of which have

184 been published since 2010 [35-75]; papers that measured serum levels of cytokines or frequencies of

185 lymphocyte subsets during acute DENV infection were not counted if the methods could not relate the

186 findings with antigen specificity. Taking advantage of newer techniques, these papers have greatly

187 expanded the number of individuals whose immune responses have been characterized- tens to

188 hundreds of subjects in each study, in comparison to fewer than 10 in most of the earlier studies. The

189 knowledge base of DENV-specific immune responses is thus more representative of the global

190 population, particularly among populations in dengue-endemic areas. 
responses- have been validated by analysis of epitope-specific T cell lines. All ELISPOT and cytokine flow

194 cytometry studies have examined the production of IFN- $\gamma$. Studies using cytokine flow cytometry have in addition measured several other effector functions, in particular TNF $\alpha$, MIP-1 $\beta$, or IL-2 production or release of cytotoxic granules (measured by capture of CD107a at the cell surface).

In vitro stimulation for detection of DENV-specific T cells was accomplished with synthetic peptides in nearly all of the recent studies. In comparison with crude antigen preparations used in earlier studies, such as DENV-infected cell lysates, synthetic peptides provide greater standardization

200 and reproducibility, and also directly provide detailed epitope localization. The large number of peptides 201 needed to provide a comprehensive analysis of all potential DENV epitopes presents a major technical 202 challenge, however. None of the studies reviewed included overlapping peptides from the full 203 proteomes of all four DENV serotypes. Weiskopf et al conducted the most comprehensive analysis [60]; 204 however, although a total of 8,000 peptides were used in the study, each subject was only tested for 205 recognition of a subset of peptides selected based on predictions of peptide binding to autologous HLA 206 class I alleles. Epitope prediction algorithms were used in 8 other studies, but many fewer candidate 207 epitopes were tested. Fourteen studies tested sets of overlapping peptides; of these, 4 studies tested 208 peptides covering the full proteome of DENV-2, whereas the remaining studies tested overlapping 209 peptides covering only a portion of the proteome, most often the NS3 protein. At least 10 studies have used HLA-peptide tetramers to analyze DENV-specific T cells either

211 directly ex vivo or after in vitro expansion [36, 38, 42, 47-49, 52, 59, 66, 73]. However, six of these 212 studied the same HLA-A*1101-restricted "GTS" epitope on the NS3 protein; in total, the remaining 4 213 studies investigated 5 other CD8 T cell epitopes and 2 CD4 T cell epitopes. Thus, conclusions based on 214 this body of data still are subject to considerable potential for bias. 
Differences between study populations in host genetics as well as prior DENV exposures continue to complicate the comparison of findings across studies. Given the difficulty in documenting or controlling these factors, there continues to be substantial interest in experimental animal models, particularly small, genetically defined animals such as mice. Several "humanized" mouse models have been studied. In several studies of transgenic mice expressing single HLA alleles, investigators

222 demonstrated recognition of candidate epitopes that were selected for predicted HLA binding;

223 subsequent testing of DENV-immune humans confirmed responses to some but not all of these epitopes $224[64,69,76-78]$. Studies of immunodeficient mice in which human immune cells were reconstituted by transfusion of human hematopoietic stem cells detected T cell responses to a limited number of known

226 human T cell epitopes $[79,80]$. These studies provide preliminary evidence that these models might 227 supplement human studies. Limited testing of heterologous secondary DENV infections was done in 228 HLA-transgenic mice [78], but no comprehensive analysis of the different possible sequences of DENV 229 infection has been conducted in these models to date.

Epitope distribution and cross-reactivity

Recent studies have greatly expanded the database of T cell epitopes identified on DENV proteins [81]. This reflects the combined effects of studying a larger number of humans with more 234 diverse HLA alleles and prior DENV infection history as well as the application of single-cell assays such as ELISPOT with large numbers of synthetic peptides. It is difficult to directly compare the results from

236 different studies, however, because of the confounding effects of differences in the numbers and 237 characteristics of the peptides used. Overlapping peptides covering over $70 \%$ of the proteome of representative strains of all four DENV serotypes have been made available to the research community 
of the published studies. Additionally, there remains a lack of consensus on the optimal criteria for

241 defining epitopes. Immunodominant epitopes- those that induce responses of high magnitude in the

242 majority (often nearly all) of subjects with the appropriate HLA allele- have generally shown similar

243 results across studies, but these represent a minority of the epitopes identified and the generalizability

244 of the observations regarding these epitopes needs to be verified.

As mentioned above, the distribution of T cell epitopes across all DENV proteins, albeit with a

predominance of epitopes on nonstructural proteins, has been reinforced by the expanded literature. A

247 need to test for responses to the entire proteome of all four DENV serotypes presents challenges for

248 performing large-scale testing of T cell responses, such as in the context of a phase II or III vaccine trial.

249 In contrast, data pointing to the immunodominance of responses to particular regions of the polyprotein

250 provide some support for more targeted testing. For example, Weiskopf et al have estimated that a pool

251 of 268 peptides would include $90 \%$ or more of CD8 T cell epitopes in any study population [72].

252 However, this conclusion is based on their approach of HLA class I epitope prediction. It is reasonable to

253 hypothesize that other immunologically important epitopes, especially HLA class II-restricted epitopes,

254 have yet to be defined. Studies have yielded conflicting data on whether the distribution of CD4 T cell

255 epitopes is similar or different from that of CD8 T cell epitopes [48, 57], with one study reporting that

256 CD4 T cells more often recognized epitopes on structural proteins [57].

257 The use of single-cell assays such as ELISPOT has complicated the interpretation of serotype-

258 cross-reactivity of T cell responses, as these assays do not assess serotype-cross-reactivity at the level of

259 individual cells. This is a particular problem in individuals who have been exposed to more than one

260 DENV serotype, either through sequential exposure or multivalent immunization. Although one study

261 concluded that serotype-specific epitopes could be defined based on sequence conservation alone [78],

262 other experimental data are directly contradictory [36, 37, 41]. Another study described a panel of CD4

263 T cell epitopes predicted to be serotype-specific based on high sequence divergence across serotypes 
264 [55]. Among participants in a cohort study, individuals who experienced an interval DENV infection

265 acquired responses to peptides of one additional serotype [74]; however, only 7 subjects were studied 266 and the DENV serotype causing the interval infection was not identified.

Several recent findings underscore the importance of clinical, virologic, and epidemiologic data

268 on individual subjects for the interpretation of T cell responses to DENV. Although measures of T cell

269 responses at the population level consistently show stronger responses to the infecting DENV serotype

270 after a primary DENV infection, exceptions to this pattern have been observed at the level of individual

271 epitopes [37, 49, 52], and the patterns of cross-reactivity have been even more difficult to predict after

272 secondary DENV infections. Several studies have also found sufficient sequence divergence within one

273 or more DENV serotype(s) to affect the T cell response [67, 82], but the clinical significance of these

274 observations is unknown.

275

T cell subsets and their effector functions

Recent studies using multiparameter flow cytometry have provided a more detailed picture of

278 the effector T cell response to DENV. As noted above, most studies have focused on type 1 cytokine-

279 producing T cells (Th1/Tc1); these studies have revealed a high degree of heterogeneity in cytokine

280 production at the individual cell level. While polyfunctional T cells expressing 3 or more effector

281 functions have been observed, there are also substantial populations of cells expressing 1 or 2 of the

282 functions measured, including cells expressing only cytokines with pro-inflammatory effects (TNF $\alpha$

283 and/or $\beta$-chemokines) $[37,49,60,67]$. Stimulation with the corresponding epitopes of different DENV

284 serotypes has been shown to alter the profile of cytokines produced, suggesting that variant epitopes

285 act as altered peptide ligands for some DENV-specific T cells [36, 37].

Comparably less is known regarding effector responses other than Th1/Tc1. Of the few studies

287 that reported data on the production of type 2 cytokines, most reported little or no production of IL-4 
except one study of very young children (mean age 7.7 months) [61]. Single studies have described

289 production of IL-17 [61] or IL-21 [57] by T cells in response to stimulation, or have observed the

290 expression of markers associated with follicular helper CD4 T cells [57] or T cells capable of homing to

291 skin [73].

292

293

Primary vs. secondary infection

294

Models of sequential infection with different DENV serotypes postulate that the immune

295 response to secondary infection will differ in several important ways from that to the primary infection:

296 a) the memory T cell response will be induced more rapidly and achieve higher levels, b) the memory

297 response will preferentially activate T cells directed at epitopes that are more highly conserved between

298 the different DENV serotypes, mainly on non-structural proteins, and c) the memory T cell response will

299 have an altered effector profile reflecting differential activation by peptides from the second DENV

300 serotype [83]. Although testing these postulates is highly relevant to understanding both protective and

301 detrimental immune responses in dengue, only a few studies have compared immune responses during

302 or after primary versus secondary DENV infections. Consistent with the predictions, differences have

303 been reported in the expression of some phenotypic markers [71], in the dominant epitopes targeted

304 [78], and in the profile of serotype cross-reactivity [52, 82]. Surprisingly, no significant differences were

305 observed in the kinetics of the response or in the peak $T$ cell frequencies during the acute infection [48,

306 52]. These studies involved only symptomatic DENV infections, however, and the intrinsic incubation

307 period prior to the onset of symptoms could not be determined. Also, the clearance of viremia may be

308 more rapid in secondary infections, as suggested by some data [84]. These significant differences could

309 have masked differences in the kinetics and magnitude of the immune response in primary versus

310 secondary infections. 
With the expanding pipeline of vaccines in clinical testing and the wider availability of the

314 requisite expertise and technology, there has been a growing body of literature describing the T cell

315 response to dengue vaccines. All of the recently published studies have involved candidate live

316 attenuated vaccines. These studies have shown that DENV-specific memory T cells, including

317 polyfunctional Th1/Tc1 cells, are induced within 21 days after vaccination of flavivirus-naïve subjects

318 [56]. In comparison to vaccination with its individual components, vaccination with the tetravalent

319 formulation of the NIH/Butantan vaccine (Table 2) preferentially induced T cell responses to peptides

320 from the more conserved non-structural proteins [70]. Interestingly, vaccination with the Sanofi Pasteur

321 chimeric DENV-YFV vaccine induced T cell responses to epitopes on DENV NS3 protein in DENV-immune

322 subjects but not in DENV-naïve subjects, suggesting that the heterologous YFV epitopes could reactivate

323 pre-existing memory CD8 T cells but not antigen-inexperienced T cells [62]. Comparison of the T cell

324 responses induced by the different dengue vaccines listed in Table 2 is not possible, however, because

325 of significant differences in study and assay design.

327 Potential contributions of T cell assays to dengue vaccine development

The area where assessment of T cell responses to dengue vaccines would clearly have greatest

329 impact is in identifying correlates of vaccine efficacy. A reliable immunological correlate of vaccine-

330 induced protective immunity would accelerate vaccine testing in different populations, regimens, or

331 epidemiological contexts. The limitations of current neutralizing antibody assays reinforce the need for a

332 better understanding of correlates of protective immunity, although the poor discriminant ability of

333 neutralizing antibody titers may point either to deficiencies in the assay or to non-antibody protective

334 mechanisms. Human cohort studies and animal experiments have found associations between T cell

335 IFN- $\gamma$ production and protective immunity $[51,60,85,86]$, supporting the potential to identify $T$ cell 
responses associated with protective immunity induced by vaccination. However, the published data are

337 quite limited. Only two studies correlated T cell responses in blood samples collected prior to exposure

338 with clinical outcomes in individual subjects $[51,87]$; both studies relied on the same prospective cohort

339 and the sample sizes were small. Also, given the difficulty in defining individuals who are fully protected

340 from infection, all subjects in these studies experienced DENV infections and comparisons were based

341 on severity of illness (hospitalized dengue versus non-hospitalized dengue in one study and subclinical

342 versus symptomatic infection in the other). Other studies measured T cell responses only during or after

343 DENV infection, a significant confounding factor for any conclusions regarding causality. This concern is

344 somewhat lessened in the case of experimental infection, where protective immunity was associated

345 with early IFN- $\gamma$ responses [88]. In light of the limitations of published data, however, it will be essential

346 to validate immunological correlates against clinical endpoints in vaccine trials.

It will be important to validate any immunological correlates independently for several different

348 vaccines, because the associations between immunological readouts and vaccine efficacy may or may

349 not be equivalent. In addition to the differences in immune response pathways that might be stimulated

350 by live versus inactivated or subunit vaccines, there are significant differences in antigenic content

351 among the dengue vaccines currently in clinical development (Table 2). This is most pronounced with

352 regard to the repertoire of flavivirus non-structural (NS) proteins, with some vaccines containing no NS

353 proteins (subunit and inactivated vaccines, although the latter may include some NS1 protein), some

354 containing NS proteins of one flavivirus, either DENV2 or the heterologous YFV, and one containing NS

355 proteins of 3 of 4 DENV serotypes. Since non-structural proteins contain the majority of T cell epitopes,

356 the repertoire of T cell responses induced by each vaccine will likely differ as well, although the resulting

357 immunological profile is difficult to predict at this stage.

A second area where measurement of T cell responses could make an important contribution is

359 in evaluating the durability of vaccine-induced protective immunity. This is likely to be of particular 
importance for dengue vaccines given the evidence that partial immunity increases the risk for more

361 severe illness. Substantial insight has been gained into how the initial activation of T cells contributes to

362 the establishment of both long-lasting T cell and B cell memory, and this process has been successfully

363 manipulated with pharmaceuticals such as rapamycin in experimental models [89, 90]. Licensed

364 vaccines against other diseases differ significantly in the durability of pathogen-specific antibodies and T

365 cells [91]; through comprehensive "systems vaccinology" approaches, early indicators of antibody and T

366 cell responses have been identified for several of these vaccines [92, 93], although further studies are

367 needed to establish their ability to predict longer-term durability of the response.

The single-cell resolution and potential to evaluate multiple T cell effector functions of newer

369 assays offer the capacity to reveal extraordinary detail on the relationships between these responses.

370 This capacity will likely be of special interest in the case of dengue vaccines, given the multivalent nature

371 of dengue vaccines, the need to provide protective immunity against all four DENV serotypes, and the

372 evidence that more severe dengue disease is associated with an inflammatory immune response. Data

373 from several studies showing the induction of polyfunctional T cells by different tetravalent dengue

374 vaccines are encouraging $[56,70,75]$. However, it is unclear whether the degree of 'polyfunctionality'

375 described is optimal; similar frequencies of polyfunctional T cells are seen after natural DENV infection, a

376 setting that does not reflect fully (i.e., tetravalent) protective immunity. Partial immunity to DENV

377 present prior to vaccination, as was seen in the majority of subjects in phase III vaccine trials in endemic

378 areas $[3,4]$, could also modify the pattern of T cell effector functions.

\section{Conclusions and recommendations}

Although assessments of pathogen-specific T cell responses have not been a priority in most

382 vaccine development efforts, we argue that dengue is a special case and that planning and preparation

383 for such assessments should be given greater emphasis. The example of natural infection illustrates the 
384 potential for both positive (protective) and negative (pathological) effects of partial immunity to DENV,

385 and potential concerns for long-term safety will likely remain a major impediment to licensure and

386 widespread uptake of dengue vaccines. The current understanding of T cell responses to DENV indicates

387 the potential for evaluations of T cell responses to accelerate vaccine design and testing by helping to

388 identify correlates of vaccine efficacy and also to reduce the risk to vaccine developers by helping to

389 understand negative outcomes of vaccine trials, should they occur [94]. Implementing analyses of T cell

390 responses in the context of upcoming dengue vaccine trials will present a number of significant logistical

391 challenges (Table 4). Based on current knowledge, it is not possible to define the assay or assays that

392 would reliably serve all of the pertinent objectives. The experience from prospective dengue cohort

393 studies $[51,87]$ and trials of other vaccines [95] does provide guidance to vaccine developers as to how

394 T cell studies can be incorporated into dengue vaccine trials. There continues to be a need for studies of

395 natural DENV infection as well as efforts to develop new technologies for assessment of T cell responses

396 to DENV. Implementation of these efforts will require ongoing support from government, industry, and

397 charitable foundations, as well as creative solutions from the scientific community. 
399 Disclaimer

400 The opinions or assertions contained herein are the private views of the authors and are not to

401 be construed as reflecting the official views of the United States Army or the United States Department

402 of Defense.

403 
[1] Plotkin SA. Correlates of protection induced by vaccination. Clinical and vaccine immunology : CVI. 2010;17:1055-65.

[2] Thomas SJ, Hombach J, Barrett A. Scientific consultation on cell mediated immunity (CMI) in dengue and dengue vaccine development. Vaccine. 2009;27:355-68.

[3] Capeding MR, Tran NH, Hadinegoro SR, Ismail HI, Chotpitayasunondh T, Chua MN, et al. Clinical efficacy and safety of a novel tetravalent dengue vaccine in healthy children in Asia: a phase 3, randomised, observer-masked, placebo-controlled trial. Lancet. 2014;384:1358-65. dengue vaccine in children in Latin America. The New England journal of medicine. 2015;372:113-23.

[5] Kara EE, Comerford I, Fenix KA, Bastow CR, Gregor CE, McKenzie DR, et al. Tailored immune

[6] Tripathi SK, Lahesmaa R. Transcriptional and epigenetic regulation of T-helper lineage specification. ImmunolRev. 2014;261:62-83.

421 [7] Cheroutre H, Husain MM. CD4 CTL: living up to the challenge. SemImmunol. 2013;25:273-81.

422 [8] Peck A, Mellins ED. Plasticity of T-cell phenotype and function: the Thelper type 17 example. Immunology. 2010;129:147-53.

424 [9] Restifo NP, Gattinoni L. Lineage relationship of effector and memory T cells. CurrOpinlmmunol. 2013;25:556-63.

[10] Gasper DJ, Tejera MM, Suresh M. CD4 T-cell memory generation and maintenance. Crit Rev Immunol. 2014;34:121-46. 
[11] Chang JT, Wherry EJ, Goldrath AW. Molecular regulation of effector and memory T cell differentiation. Nature immunology. 2014;15:1104-15.

[12] Plotkin SA. Correlates of protection induced by vaccination. Clin Vaccine Immunol. 2010;17:105565.

[13] Thakur A, Pedersen LE, Jungersen G. Immune markers and correlates of protection for vaccine induced immune responses. Vaccine. 2012;30:4907-20.

[14] Finak G, Jiang W, Krouse K, Wei C, Sanz I, Phippard D, et al. High-throughput flow cytometry data normalization for clinical trials. Cytometry A. 2014;85:277-86.

[15] Saade F, Gorski SA, Petrovsky N. Pushing the frontiers of T-cell vaccines: accurate measurement of human T-cell responses. Expert Rev Vaccines. 2012;11:1459-70.

[16] Dubey S, Clair J, Fu TM, Guan L, Long R, Mogg R, et al. Detection of HIV vaccine-induced cellmediated immunity in HIV-seronegative clinical trial participants using an optimized and validated enzyme-linked immunospot assay. J Acquir Immune Defic Syndr. 2007;45:20-7.

[17] Horton H, Thomas EP, Stucky JA, Frank I, Moodie Z, Huang Y, et al. Optimization and validation of an 8-color intracellular cytokine staining (ICS) assay to quantify antigen-specific T cells induced by vaccination. J Immunol Methods. 2007;323:39-54.

[18] Bjornson ZB, Nolan GP, Fantl WJ. Single-cell mass cytometry for analysis of immune system functional states. Curr Opin Immunol. 2013;25:484-94.

[19] Chattopadhyay PK, Roederer M. A mine is a terrible thing to waste: high content, single cell technologies for comprehensive immune analysis. Am J Transplant. 2015;15:1155-61.

[20] Roederer M. Interpretation of cellular proliferation data: avoid the panglossian. Cytometry A. 2011;79:95-101. 
[21] Plessy C, Desbois L, Fujii T, Carninci P. Population transcriptomics with single-cell resolution: a new field made possible by microfluidics: a technology for high throughput transcript counting and data-driven definition of cell types. Bioessays. 2013;35:131-40.

[22] Trautmann L, Sekaly RP. Solving vaccine mysteries: a systems biology perspective. Nat Immunol. 2011;12:729-31.

[23] Manrique A, Adams E, Barouch DH, Fast P, Graham BS, Kim JH, et al. The immune space: a concept and template for rationalizing vaccine development. AIDS Res Hum Retroviruses. 2014;30:101722.

[24] Todd CA, Sanchez AM, Garcia A, Denny TN, Sarzotti-Kelsoe M. Implementation of Good Clinical Laboratory Practice (GCLP) guidelines within the External Quality Assurance Program Oversight Laboratory (EQAPOL). J Immunol Methods. 2014;409:91-8.

[25] Sanchez AM, Denny TN, O'Gorman M. Introduction to a Special Issue of the Journal of Immunological Methods: Building global resource programs to support HIV/AIDS clinical trial studies. J Immunol Methods. 2014;409:1-5.

[26] Staats JS, Enzor JH, Sanchez AM, Rountree W, Chan C, Jaimes M, et al. Toward development of a comprehensive external quality assurance program for polyfunctional intracellular cytokine staining assays. J Immunol Methods. 2014;409:44-53.

[27] Rountree W, Vandergrift N, Bainbridge J, Sanchez AM, Denny TN. Statistical methods for the assessment of EQAPOL proficiency testing: ELISpot, Luminex, and Flow Cytometry. J Immunol Methods. 2014;409:72-81.

[28] Sambor A, Garcia A, Berrong M, Pickeral J, Brown S, Rountree W, et al. Establishment and maintenance of a PBMC repository for functional cellular studies in support of clinical vaccine trials. J Immunol Methods. 2014;409:107-16. 
[29] Sanchez AM, DeMarco CT, Hora B, Keinonen S, Chen Y, Brinkley C, et al. Development of a contemporary globally diverse HIV viral panel by the EQAPOL program. J Immunol Methods. 2014;409:117-30.

[30] Garcia A, Keinonen S, Sanchez AM, Ferrari G, Denny TN, Moody MA. Leukopak PBMC sample processing for preparing quality control material to support proficiency testing programs. J Immunol Methods. 2014;409:99-106.

[31] Britten CM, Janetzki S, Butterfield LH, Ferrari G, Gouttefangeas C, Huber C, et al. T cell assays and MIATA: the essential minimum for maximum impact. Immunity. 2012;37:1-2.

[32] Janetzki S, Britten CM, Kalos M, Levitsky HI, Maecker HT, Melief CJ, et al. "MIATA"-minimal information about T cell assays. Immunity. 2009;31:527-8.

[33] Kurane I, Ennis FA. Immunity and immunopathology in dengue virus infections. SemImmunol. 1992;4:121-7.

[34] Rothman AL. Immunology and immunopathogenesis of dengue disease. Adv Virus Res. 2003;60:397-419.

[35] Simmons CP, Dong T, Chau NV, Dung NT, Chau TN, Thao le TT, et al. Early T-cell responses to dengue virus epitopes in Vietnamese adults with secondary dengue virus infections. J Virol. 2005;79:5665-75.

[36] Mangada MM, Rothman AL. Altered cytokine responses of dengue-specific CD4+ T cells to heterologous serotypes. J Immunol. 2005;175:2676-83.

[37] Bashyam HS, Green S, Rothman AL. Dengue virus-reactive CD8+ T cells display quantitative and qualitative differences in their response to variant epitopes of heterologous viral serotypes. J Immunol. 2006;176:2817-24. 
[38] Mongkolsapaya J, Duangchinda T, Dejnirattisai W, Vasanawathana S, Avirutnan P, Jairungsri A, et al. T cell responses in dengue hemorrhagic fever: are cross-reactive T cells suboptimal? J Immunol. 2006;176:3821-9.

[39] de la CSB, Garcia G, Perez AB, Morier L, Alvarez M, Kouri G, et al. Ethnicity and difference in dengue virus-specific memory T cell responses in Cuban individuals. Viral Immunol. 2006;19:662-8.

[40] Appanna R, Huat TL, See LL, Tan PL, Vadivelu J, Devi S. Cross-reactive T-cell responses to the nonstructural regions of dengue viruses among dengue fever and dengue hemorrhagic fever patients in Malaysia. Clinical and vaccine immunology : CVI. 2007;14:969-77.

[41] Imrie A, Meeks J, Gurary A, Sukhbataar M, Kitsutani P, Effler P, et al. Differential functional avidity of dengue virus-specific T-cell clones for variant peptides representing heterologous and previously encountered serotypes. J Virol. 2007;81:10081-91.

[42] Dong T, Moran E, Vinh Chau N, Simmons C, Luhn K, Peng Y, et al. High pro-inflammatory cytokine secretion and loss of high avidity cross-reactive cytotoxic T-cells during the course of secondary dengue virus infection. PLoS ONE. 2007;2:e1192.

[43] Wen JS, Jiang LF, Zhou JM, Yan HJ, Fang DY. Computational prediction and identification of dengue virus-specific CD4(+) T-cell epitopes. Virus research. 2008;132:42-8.

[44] Moran E, Simmons C, Vinh Chau N, Luhn K, Wills B, Dung NP, et al. Preservation of a critical epitope core region is associated with the high degree of flaviviral cross-reactivity exhibited by a denguespecific CD4+ T cell clone. Eur J Immunol. 2008;38:1050-7.

[45] Guy B, Nougarede N, Begue S, Sanchez V, Souag N, Carre M, et al. Cell-mediated immunity induced by chimeric tetravalent dengue vaccine in naive or flavivirus-primed subjects. Vaccine. 2008;26:5712-21.

[46] Wen J, Duan Z, Jiang L. Identification of a dengue virus-specific HLA-A*0201-restricted CD8+ T cell epitope. JMedVirol. 2010;82:642-8. 
[47] Dung NT, Duyen HT, Thuy NT, Ngoc TV, Chau NV, Hien TT, et al. Timing of CD8+ T cell responses in relation to commencement of capillary leakage in children with dengue. J Immunol. 2010;184:7281-7.

[48] Duangchinda T, Dejnirattisai W, Vasanawathana S, Limpitikul W, Tangthawornchaikul N, Malasit P, et al. Immunodominant T-cell responses to dengue virus NS3 are associated with DHF. Proc Natl Acad Sci U S A. 2010;107:16922-7.

[49] Friberg H, Burns L, Woda M, Kalayanarooj S, Endy TP, Stephens HA, et al. Memory CD8(+) T cells from naturally acquired primary dengue virus infection are highly cross-reactive. ImmunolCell Biol. 2011;89:122-9.

[50] Sun P, Beckett C, Danko J, Burgess T, Liang Z, Kochel T, et al. A dendritic cell-based assay for measuring memory T cells specific to dengue envelope proteins in human peripheral blood. JVirolMeth. 2011;173:175-81.

[51] Hatch S, Endy TP, Thomas S, Mathew A, Potts J, Pazoles P, et al. Intracellular cytokine production by dengue virus-specific T cells correlates with subclinical secondary infection. J Infect Dis. 2011;203:1282-91.

[52] Friberg H, Bashyam H, Toyosaki-Maeda T, Potts JA, Greenough T, Kalayanarooj S, et al. Crossreactivity and expansion of dengue-specific T cells during acute primary and secondary infections in humans. Sci Rep. 2011;1:51.

[53] Testa JS, Shetty V, Sinnathamby G, Nickens Z, Hafner J, Kamal S, et al. Conserved MHC class Ipresented dengue virus epitopes identified by immunoproteomics analysis are targets for crossserotype reactive T-cell response. The Journal of infectious diseases. 2012;205:647-55.

[54] Malavige GN, Huang LC, Salimi M, Gomes L, Jayaratne SD, Ogg GS. Cellular and cytokine correlates of severe dengue infection. PLoS ONE. 2012;7:e50387. 
542 [55] Malavige GN, McGowan S, Atukorale V, Salimi M, Peelawatta M, Fernando N, et al. Identification of

543 serotype-specific T cell responses to highly conserved regions of the dengue viruses.

$544 \quad$ ClinExplmmunol. 2012;168:215-23.

545 [56] Lindow JC, Borochoff-Porte N, Durbin AP, Whitehead SS, Fimlaid KA, Bunn JY, et al. Primary

$546 \quad$ vaccination with low dose live dengue 1 virus generates a proinflammatory, multifunctional T

547 cell response in humans. PLoS neglected tropical diseases. 2012;6:e1742.

548 [57] Rivino L, Kumaran EA, Jovanovic V, Nadua K, Teo EW, Pang SW, et al. Differential targeting of viral

549 components by CD4+ versus CD8+ T lymphocytes in dengue virus infection. JVirol.

$550 \quad$ 2013;87:2693-706.

551 [58] Rivino L, Tan AT, Chia A, Kumaran EA, Grotenbreg GM, MacAry PA, et al. Defining CD8+ T cell

552 determinants during human viral infection in populations of Asian ethnicity. JImmunol.

$553 \quad 2013 ; 191: 4010-9$.

554 [59] Chang CX, Tan AT, Or MY, Toh KY, Lim PY, Chia AS, et al. Conditional ligands for Asian HLA variants

555 facilitate the definition of CD8+ T-cell responses in acute and chronic viral diseases.

$556 \quad$ EurJImmunol. 2013;43:1109-20.

557 [60] Weiskopf D, Angelo MA, de Azeredo EL, Sidney J, Greenbaum JA, Fernando AN, et al.

558 Comprehensive analysis of dengue virus-specific responses supports an HLA-linked protective

559 role for CD8+ T cells. Proceedings of the National Academy of Sciences of the United States of

$560 \quad$ America. 2013;110:E2046-53.

561 [61] Talarico LB, Bugna J, Wimmenauer V, Espinoza MA, Quipildor MO, Hijano DR, et al. Thelper type 2

562 bias and type 17 suppression in primary dengue virus infection in infants and young children.

$563 \quad$ TransRoyal SocTropMedHyg. 2013;107:411-9. 
564 [62] Harenberg A, Begue S, Mamessier A, Gimenez-Fourage S, Ching Seah C, Wei Liang A, et al. Persistence of Th1/Tc1 responses one year after tetravalent dengue vaccination in adults and adolescents in Singapore. Hum Vaccin Immunother. 2013;9:2317-25.

[63] Malavige GN, Jeewandara C, Alles KM, Salimi M, Gomes L, Kamaladasa A, et al. Suppression of virus specific immune responses by IL-10 in acute dengue infection. PLoS neglected tropical diseases. 2013;7:e2409.

[64] Nascimento EJ, Mailliard RB, Khan AM, Sidney J, Sette A, Guzman N, et al. Identification of conserved and HLA promiscuous DENV3 T-cell epitopes. PLoS neglected tropical diseases. 2013;7:e2497.

[65] Nguyen TH, Nguyen TH, Vu TT, Farrar J, Hoang TL, Dong TH, et al. Corticosteroids for dengue - why don't they work? PLoS neglected tropical diseases. 2013;7:e2592.

[66] Townsley E, Woda M, Thomas SJ, Kalayanarooj S, Gibbons RV, Nisalak A, et al. Distinct activation phenotype of a highly conserved novel HLA-B57-restricted epitope during dengue virus infection. Immunology. 2014;141:27-38.

[67] Piazza P, Campbell D, Marques E, Hildebrand WH, Buchli R, Mailliard R, et al. Dengue virus-infected human dendritic cells reveal hierarchies of naturally expressed novel NS3 CD8 T cell epitopes. ClinExplmmunol. 2014;177:696-702.

[68] Comber JD, Karabudak A, Huang X, Piazza PA, Marques ET, Philip R. Dengue virus specific dual HLA binding T cell epitopes induce CD8+ T cell responses in seropositive individuals. Hum Vaccin Immunother. 2014;10:3531-43.

[69] Duan Z, Guo J, Huang X, Liu H, Chen X, Jiang M, et al. Identification of cytotoxic T lymphocyte epitopes in dengue virus serotype 1. JMedVirol. 2015;87:1077-89. 
[70] Weiskopf D, Angelo MA, Bangs DJ, Sidney J, Paul S, Peters B, et al. The human CD8+ T cell responses induced by a live attenuated tetravalent dengue vaccine are directed against highly conserved epitopes. JVirol. 2015;89:120-8.

[71] Weiskopf D, Bangs DJ, Sidney J, Kolla RV, De Silva AD, de Silva AM, et al. Dengue virus infection elicits highly polarized CX3CR1+ cytotoxic CD4+ T cells associated with protective immunity. Proceedings of the National Academy of Sciences of the United States of America. 2015;112:E4256-63.

[72] Weiskopf D, Cerpas C, Angelo MA, Bangs DJ, Sidney J, Paul S, et al. Human CD8+ T-Cell Responses Against the 4 Dengue Virus Serotypes Are Associated With Distinct Patterns of Protein Targets. The Journal of infectious diseases. 2015.

[73] Rivino L, Kumaran EA, Thein TL, Too CT, Gan VC, Hanson BJ, et al. Virus-specific T lymphocytes home to the skin during natural dengue infection. Sci Transl Med. 2015;7:278ra35.

[74] Jeewandara C, Adikari TN, Gomes L, Fernando S, Fernando RH, Perera MK, et al. Functionality of dengue virus specific memory $\mathrm{T}$ cell responses in individuals who were hospitalized or who had mild or subclinical dengue infection. PLoS neglected tropical diseases. 2015;9:e0003673.

[75] Chu H, George SL, Stinchcomb DT, Osorio JE, Partidos CD. CD8+ T-cell Responses in Flavivirus-Naive Individuals Following Immunization with a Live-Attenuated Tetravalent Dengue Vaccine Candidate. The Journal of infectious diseases. 2015.

[76] Duan ZL, Liu HF, Huang X, Wang SN, Yang JL, Chen XY, et al. Identification of conserved and HLAA*2402-restricted epitopes in Dengue virus serotype 2. Virus research. 2015;196:5-12.

[77] Weiskopf D, Yauch LE, Angelo MA, John DV, Greenbaum JA, Sidney J, et al. Insights into HLArestricted T cell responses in a novel mouse model of dengue virus infection point toward new implications for vaccine design. J Immunol. 2011;187:4268-79. 
[78] Weiskopf D, Angelo MA, Sidney J, Peters B, Shresta S, Sette A. Immunodominance changes as a function of the infecting dengue virus serotype and primary versus secondary infection. JVirol. 2014;88:11383-94.

[79] Jaiswal S, Pearson T, Friberg H, Shultz LD, Greiner DL, Rothman AL, et al. Dengue virus infection and virus-specific HLA-A2 restricted immune responses in humanized NOD-scid IL2rgammanull mice. PLOS ONE. 2009;4:e7251.

[80] Jaiswal S, Pazoles P, Woda M, Shultz LD, Greiner DL, Brehm MA, et al. Enhanced humoral and HLAA2-restricted dengue virus-specific T-cell responses in humanized BLT NSG mice. Immunology. 2012;136:334-43.

[81] Vaughan K, Greenbaum J, Blythe M, Peters B, Sette A. Meta-analysis of all immune epitope data in the Flavivirus genus: inventory of current immune epitope data status in the context of virus immunity and immunopathology. Viral Immunol. 2010;23:259-84.

[82] Mongkolsapaya J, Dejnirattisai W, Xu X, Vasanawathana S, Tangthawornchaikul N, Chairunsri A, et al. Original antigenic sin and apoptosis in the pathogenesis of dengue hemorrhagic fever. Nature Med. 2003;9:921-7.

[83] Rothman AL. Cellular immunology of sequential dengue virus infection and its role in disease pathogenesis. Curr Top Microbiol Immunol. 2010;338:83-98.

[84] Vaughn DW, Green S, Kalayanarooj S, Innis BL, Nimmannitya S, Suntayakorn S, et al. Dengue viremia titer, antibody response pattern and virus serotype correlate with disease severity. JInfectDis. 2000;181:2-9.

[85] Gil L, Bernardo L, Pavon A, Izquierdo A, Valdes I, Lazo L, et al. Recombinant nucleocapsid-like particles from dengue- 2 induce functional serotype-specific cell-mediated immunity in mice. The Journal of general virology. 2012;93:1204-14. 
632 633

634

635

636

637

638

639

640

641

642

643

644

645

646

647

648

649

650

651

652

653
[86] Yauch LE, Prestwood TR, May MM, Morar MM, Zellweger RM, Peters B, et al. CD4+ T cells are not required for the induction of dengue virus-specific CD8+ T cell or antibody responses but contribute to protection after vaccination. J Immunol. 2010;185:5405-16.

[87] Mangada MM, Endy TP, Nisalak A, Chunsuttiwat S, Vaughn DW, Libraty DH, et al. Dengue-specific T cell responses in peripheral blood mononuclear cells obtained prior to secondary dengue virus infections in Thai schoolchildren. JInfectDis. 2002;185:1697-703.

[88] Gunther VJ, Putnak R, Eckels KH, Mammen MP, Scherer JM, Lyons A, et al. A human challenge model for dengue infection reveals a possible protective role for sustained interferon gamma levels during the acute phase of illness. Vaccine. 2011;29:3895-904.

[89] Araki K, Turner AP, Shaffer VO, Gangappa S, Keller SA, Bachmann MF, et al. mTOR regulates memory CD8 T-cell differentiation. Nature. 2009;460:108-12.

[90] Turner AP, Shaffer VO, Araki K, Martens C, Turner PL, Gangappa S, et al. Sirolimus enhances the magnitude and quality of viral-specific CD8+ T-cell responses to vaccinia virus vaccination in rhesus macaques. Am J Transplant. 2011;11:613-8.

[91] Amanna IJ, Carlson NE, Slifka MK. Duration of humoral immunity to common viral and vaccine antigens. The New England journal of medicine. 2007;357:1903-15.

[92] Querec TD, Akondy RS, Lee EK, Cao W, Nakaya HI, Teuwen D, et al. Systems biology approach predicts immunogenicity of the yellow fever vaccine in humans. Nature immunology. 2009;10:116-25.

[93] Tan Y, Tamayo P, Nakaya H, Pulendran B, Mesirov JP, Haining WN. Gene signatures related to B-cell proliferation predict influenza vaccine-induced antibody response. EurJImmunol. 2014;44:28595. 
654 [94] Hadinegoro SR, Arredondo-Garcia JL, Capeding MR, Deseda C, Chotpitayasunondh T, Dietze R, et al. 655 Efficacy and Long-Term Safety of a Dengue Vaccine in Regions of Endemic Disease. The New $656 \quad$ England journal of medicine. 2015.

657 [95] Haynes BF, Gilbert PB, McElrath MJ, Zolla-Pazner S, Tomaras GD, Alam SM, et al. Immune-correlates 658 analysis of an HIV-1 vaccine efficacy trial. N Engl J Med. 2012;366:1275-86.

659

660 
661 Table 1. Characteristics defining different subsets of effector CD4 T cells.

\begin{tabular}{|c|c|c|c|c|}
\hline Subset & $\begin{array}{l}\text { Cytokine(s) } \\
\text { produced }\end{array}$ & $\begin{array}{l}\text { Chemokine } \\
\text { receptor(s) }\end{array}$ & $\begin{array}{c}\text { Transcription } \\
\text { factor(s) }\end{array}$ & Comment \\
\hline Th1 & IFN- $\gamma$ & CXCR3 & T-Bet & Cellular immunity \\
\hline Th2 & IL-4, IL-5, IL-13 & $\begin{array}{l}\text { CCR3, CCR4, } \\
\text { CCR8 }\end{array}$ & GATA-3 & Humoral immunity \\
\hline Th17 & IL-17 & $\begin{array}{l}\text { CCR2, CCR4, } \\
\text { CCR6 }\end{array}$ & ROR $\gamma \mathrm{t}$ & Inflammation \\
\hline Th9 & IL-9 & $\begin{array}{l}\text { CCR3, CCR6, } \\
\text { CXCR3 }\end{array}$ & PU.1 & Mucosal immunity \\
\hline Th22 & IL-22 & CCR4, CCR10 & AhR & Parasites \\
\hline Tfh & IL-21 & CXCR5 & $\mathrm{Bcl}-6$ & B cell help \\
\hline iTreg & IL-10, TGF- $\beta$ & CCR6 & FoxP3 & Immunosuppression, tolerance \\
\hline
\end{tabular}

662 
664 Table 2. T cell antigenic content of dengue vaccine candidates in clinical development.

\begin{tabular}{|c|c|c|}
\hline Vaccine developer & Structural proteins & Non-structural proteins \\
\hline $\begin{array}{l}\text { Live, attenuated (chimeric } \\
\text { flaviviruses) }\end{array}$ & & \\
\hline Sanofi Pasteur & C: YFV; pre-M, E: DENV1-4 & NS1-5: YFV \\
\hline Takeda & C: DENV2; pre-M, E: DENV1-4 & NS1-5: DENV2 \\
\hline $\mathrm{NIH} /$ Butantan & $\begin{array}{l}\text { C: DENV1/3/4; pre-M, E: DENV1- } \\
4\end{array}$ & NS1-5: DENV1/3/4 \\
\hline Purified inactivated & & \\
\hline WRAIR/GSK & C, pre-M, E: DENV1-4 & None (? NS1) \\
\hline Subunit & & \\
\hline Merck & E (80\%): DENV1-4 & None \\
\hline
\end{tabular}

665

666 
Table 3. Advantages and disadvantages of different methodologies for evaluation of pathogen-specific T

668 cell responses.

\begin{tabular}{|c|c|c|c|}
\hline Method & Functions measured & Advantages & Disadvantages \\
\hline Ex vivo (no stimulation & & & \\
\hline $\begin{array}{l}\text { Flow cytometry (HLA- } \\
\text { peptide tetramer } \\
\text { staining) }\end{array}$ & $\begin{array}{l}\text { Antigen specificity } \\
\text { Phenotype }\end{array}$ & $\begin{array}{l}\text { Quantitative readout of } \\
\text { cell frequency } \\
\text { Independent of cell } \\
\text { responsiveness }\end{array}$ & $\begin{array}{l}\text { Limited to one or few } \\
\text { epitopes } \\
\text { Not reflective of cell } \\
\text { function } \\
\text { Costly }\end{array}$ \\
\hline $\begin{array}{l}\text { Short-term in vitro }(\leq 1 \\
\text { day) }\end{array}$ & & & \\
\hline $\begin{array}{l}\text { Flow cytometry/mass } \\
\text { cytometry } \\
\text { (intracellular } \\
\text { staining) }\end{array}$ & $\begin{array}{l}\text { Cytokine production } \\
\text { Degranulation } \\
\text { (cytolysis) } \\
\text { Phenotype }\end{array}$ & $\begin{array}{l}\text { Quantitative readout of } \\
\text { cell frequency } \\
\text { Multiple functions } \\
\text { assessed }\end{array}$ & $\begin{array}{l}\text { Costly } \\
\text { Specimen requirement } \\
\text { high }\end{array}$ \\
\hline ELISPOT & $\begin{array}{l}\text { Cytokine secretion } \\
\text { Granzyme release }\end{array}$ & $\begin{array}{l}\text { Quantitative readout of } \\
\text { cell frequency } \\
\text { Technical ease } \\
\text { Reproducibility } \\
\text { Specimen requirement } \\
\text { low/modest }\end{array}$ & $\begin{array}{l}\text { One (or two) functions } \\
\text { assessed per cell }\end{array}$ \\
\hline
\end{tabular}




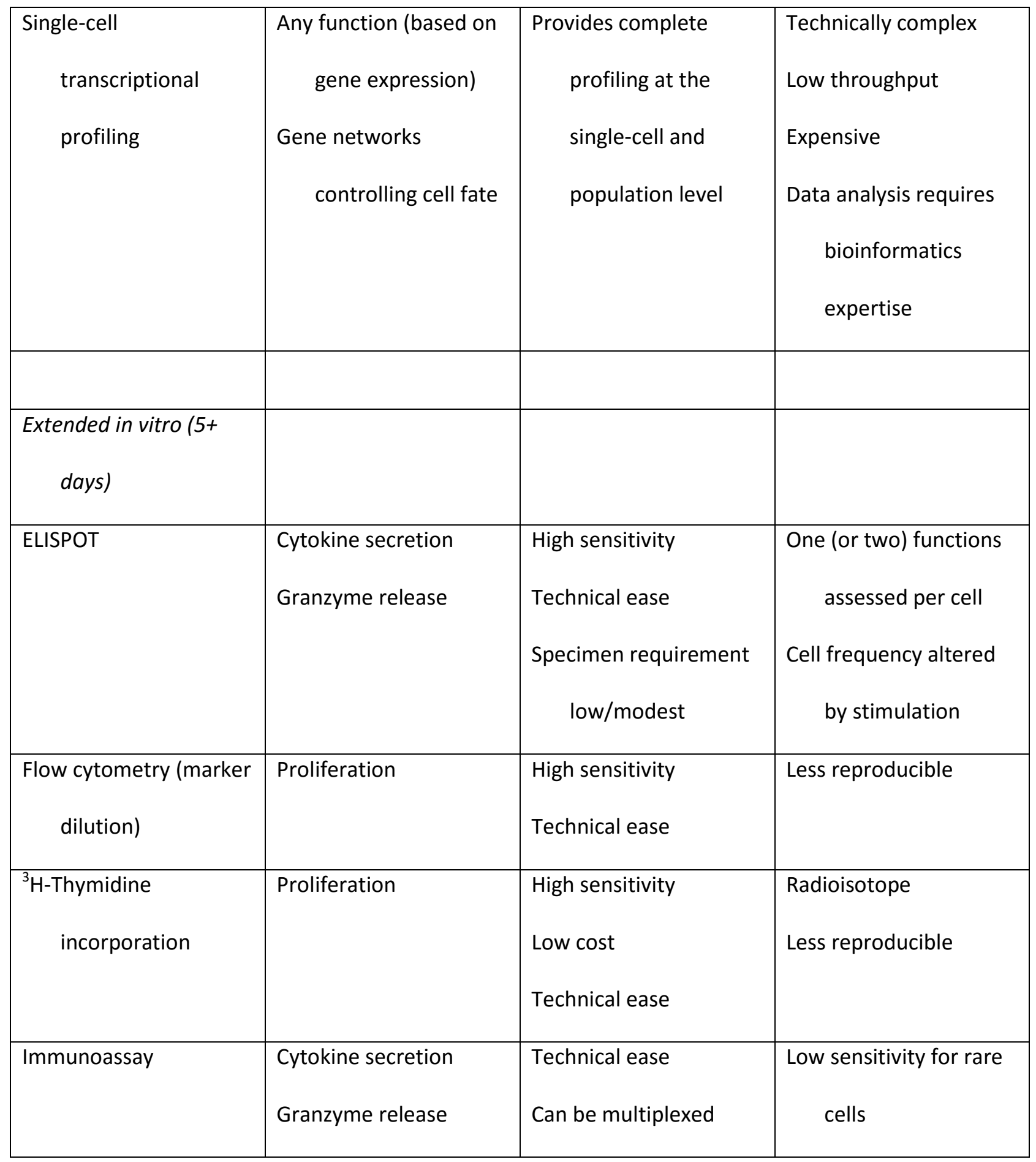




\begin{tabular}{|c|l|l|l|}
\hline $\begin{array}{c}\text { Cloning (characterize } \\
\text { with other assays) }\end{array}$ & Multiple & Multiple functions & Low throughput (few \\
& & measured & cells evaluated) \\
crossreactivity & Costly \\
& & Technical complexity \\
\hline
\end{tabular}

669

670 
671 Table 4. Logistical issues and recommendations for assessment of T cell responses to dengue vaccines.

\begin{tabular}{|c|c|}
\hline Issues & Recommendations \\
\hline $\begin{array}{l}\text { Technical expertise and infrastructure needed for } \\
\text { collection of viable PBMC }\end{array}$ & $\begin{array}{l}\text { Study site development and staff training and } \\
\text { supervision }\end{array}$ \\
\hline $\begin{array}{l}\text { Need to measure responses to all four DENV } \\
\text { serotypes (and separately for structural } \\
\text { and non-structural antigens) }\end{array}$ & $\begin{array}{l}\text { Collect adequate volumes of blood for assessment } \\
\text { of T cell responses }\end{array}$ \\
\hline $\begin{array}{l}\text { Immune correlates of vaccine efficacy have not yet } \\
\text { been defined }\end{array}$ & $\begin{array}{l}\text { Apply a diverse suite of assays of T cell function } \\
\text { and specificity }\end{array}$ \\
\hline $\begin{array}{l}\text { Variation in HLA alleles and prior DENV exposure } \\
\text { history in vaccine recipients }\end{array}$ & $\begin{array}{l}\text { Enroll adequate numbers and diversity of subjects } \\
\text { in assessments of T cell responses to } \\
\text { vaccination } \\
\text { Collect blood samples before and after vaccination } \\
\text { for T cell assays }\end{array}$ \\
\hline $\begin{array}{l}\text { Lack of high-throughput assays to measure cross- } \\
\text { reactivity at single-cell level }\end{array}$ & Development of new assay technologies \\
\hline
\end{tabular}

